\title{
LA APLICACIÓN JUDICIAL DE LA CDFUE; UN DECÁLOGO A PARTIR DE LA JURISPRUDENCIA DEL TRIBUNAL DE JUSTICIA DE LA UNIÓN EUROPEA $^{1}$
}

\author{
RAFAEL BUSTOS GISBERT \\ Catedrático $(A)$ de Derecho Constitucional \\ Universidad de Salamanca \\ Profesor de la Escuela Judicial
}

\section{SUMARIO}

I. Introducción. II. Ámbito de aplicación de la CDFUE. III. Efectos de la aplicación de la Carta sobre los derechos fundamentales utilizados por el juez. IV. Cambios en la posición del Juez como consecuencia de la vigencia de la CDFUE. V. Reflexiones finales.

\section{INTRODUCCIÓN}

La Carta de Derechos Fundamentales de la Unión Europea (en adelante CDFUE) entró plenamente en vigor con el Tratado de Lisboa. Eso no implica que la jurisprudencia del Tribunal de Justicia de la UE (en adelante TJUE) no se hubiera ocupado con anterioridad de los derechos fundamentales aplicables al ordenamiento jurídico de la Unión, así como de los principios que debían regir las relaciones de aquellos con las normas constitucionales nacionales en materia de derechos. Pero la entrada en vigor de la CDFUE ha permitido que el TJUE cada vez con mayor frecuencia y profundidad se esté ocupando de la delimitación y alcance de tales derechos. En este sentido la Carta supone algo más que la mera codificación de las anteriores «tradiciones constitucionales comunes de los Estados miembros», si bien no ha cambiado sustancialmente la forma en que el TJUE

1 Una versión anterior del presente trabajo fue presentado en el curso: «La jurisdicción constitucional en la tutela de los Derechos Fundamentales de la UE» en el marco de los Cursos de Verano de la Universidad del País Vasco, en Julio de 2016. 
entendía los derechos fundamentales en el ámbito de la UE. En tal sentido debe reseñarse que ha servido como catalizador del desarrollo de un cada vez más rico discurso de los derechos en las argumentaciones del Tribunal. Por otra parte, también ha producido una creciente preocupación en los poderes judiciales de los Estados miembros que, al disponer de un texto expreso, se han animado, en su función de jueces de la Unión, a solicitar interpretaciones sobre la Carta al Tribunal de Justicia mediante un uso frecuente del citado texto en sus cuestiones prejudiciales.

De este modo el TJUE ha ido adoptando claramente un papel de liderazgo importante en materia de interpretación de derechos fundamentales. Papel solicitado por los jueces en la medida en que su condición de jueces europeos requiere unas aclaraciones e instrucciones en su labor, ahora claramente expresada pero que siempre ha estado presente, de instancias de protección de los derechos fundamentales de la Unión ante un escenario inédito en sus tradiciones constitucionales.

Efectivamente, la CDFUE crea una situación inédita en el panorama europeo de protección de los derechos desde la perspectiva del juez que se encuentra ahora ante tres listados de derechos fundamentales vigentes en España: el contenido en la Constitución Española de 1978, el recogido en el Convenio Europeo de Derechos Humanos (CEDH) y el declarado en la CDFUE. Con ello aparecen problemas en la práctica judicial que hasta ahora en su mayoría habían permanecido latentes ante la inexistencia de la codificación de los derechos fundamentales en la UE. El más evidente es la aparición de tres instancias jurisdiccionales máximas respecto a los derechos que operan en ámbitos no totalmente separados y que interpretan textos que no son idénticos entre sí: el Tribunal de Justicia de la Unión Europea (TJUE) respecto a la CDFUE; el Tribunal Constitucional (TC) respecto a la Constitución y el Tribunal Europeo de Derechos Humanos (TEDH) respecto al CEDH. Las preguntas deducibles de esta situación son múltiples y de gran entidad. Hace relativamente poco tiempo nos hacíamos tales preguntas en la presentación de un curso de formación continua del Consejo General del Poder Judicial sobre la aplicación de la Carta ${ }^{2}$ ¿ ¿Cuándo se aplican unas y otras declaraciones?; ¿tienen el mismo fundamento constitucional, y con ello los mismos efectos, las declaraciones contenidas en el CEDH y en la CDFUE?; ¿qué diferencias hay entre la aplicación del CEDH y la de la CDFUE?, ¿qué divergencias hay entre los deberes de sometimiento a la jurisprudencia del TEDH y del TJUE?; ¿qué ha de hacer el juez nacional actuando cómo juez de la Unión cuando se alegan derechos reconocidos en la Carta a la vista de la inexistencia de procedimiento específico alguno de protección de derechos en el ámbito de la UE?; ¿qué efectos interpretativos tienen las decisiones de las más altas instancias judiciales

2 Se trata del curso celebrado en abril de 2015 y 2016 en Madrid; organizado por el servicio de formación continua del CGPJ y titulado «La aplicación judicial de la CDFUE». De este curso y de las propuestas y opiniones de los profesores y participantes en el mismo surgen las principales ideas expuestas en el texto. 
de cada ordenamiento sobre el aplicador del derecho?; ¿cómo se relacionan los textos entre sí?; ¿qué debe hacer el juzgador cuando encuentre jurisprudencias no totalmente coincidentes entre TC, TJUE y TEDH?; ¿qué efecto tiene sobre la CDFUE la no pertenencia de la UE al sistema previsto en el CEDH y con ello no estar sometido a la jurisdicción del TEDH?; ¿se ha de producir algún cambio relevante en la actuación de los tribunales españoles cuando la UE culmine su proceso de incorporación al $\mathrm{CEDH}$ ?; ¿cuál es el sentido de las cláusulas interpretativas de la CDFUE?.

No se pretende en este breve trabajo resolver todas esas cuestiones. Al contrario, nuestro objetivo es mucho más modesto. Nuestro estudio es, sobre todo, un análisis de cómo ha de producirse la aplicación judicial de los derechos de la Carta en España. Esto es, no se trata de un artículo sobre interpretación constitucional sino de constitutional adjudication a partir, fundamentalmente, de la jurisprudencia del TJUE y de su interacción con el ordenamiento jurídico español. Para ello ofrecemos un decálogo orientador de la actuación del juez cuando se encuentre ante la necesidad de aplicar la CDFUE. Comenzaremos el ensayo estableciendo cuál es el ámbito de aplicación de la Carta para concretar, a continuación, cuáles son los efectos de usar la Carta en los derechos fundamentales que efectivamente ha de aplicar el Juez y las consecuencias en la posición del juez como garante de los derechos. Concluiremos con una serie de reflexiones conclusivas.

\section{AMBITO DE APLICACIÓN DE LA CDFUE}

1. La aplicación de la CDFUE exige la presencia de un vínculo con el Derecho de la Unión Europea. Por ello la primera operación en la aplicación judicial de los derechos contenidos en la Carta es la determinación de si existe o no dicho vínculo. Esto es, si estamos o no en el ámbito de aplicación del Derecho de la UE

Desde el principio debe apuntarse que la Carta, a los efectos de su aplicación judicial en España, presenta una doble naturaleza. Por una parte es la tabla de derechos positivada y codificada de la Unión Europea. Es, si se quiere, el bill of rights de la UE; uno de los componentes esenciales de lo que podríamos llamar la no sistematizada constitución de la Unión. Pero, además, es para el juez español un tratado de derechos fundamentales que como tal ha de servir de parámetro interpretativo de los derechos reconocidos en la Constitución ex art. 10.2 CE.

Esta doble virtualidad de la Carta no es consecuencia del texto en sí mismo, no es una exigencia del Derecho de la Unión y no es, a nuestro juicio, una derivación natural e inevitable de la propia Constitución española.

Efectivamente, una de las pocas explicaciones (jurídicas) que podemos dar a la poco natural forma de reconocer la CDFUE en el TUE a partir de su formulación 
en Lisboa ${ }^{3}$, es precisamente la intención de no convertir a la Carta en parte integrante de los tratados constitutivos de la UE, sino una suerte de texto interno reconocido o aceptado por dichos tratados como texto de los derechos de la propia Unión. No es, por tanto, estricto sensu un tratado de la UE.

Sin embargo, el legislador español fue muy claro siguiendo por otra parte la estela que ya le había marcado con anterioridad el Tribunal Constitucional usando la Carta como tratado de derechos a efectos interpretativos, aunque no estuviera promulgada o todavía no hubiera entrado en vigor (en la STC 292/2000 antes de su promulgación y en la STC 138/2005 una vez incorporada a la no nata constitución europea). El doble carácter de la Carta, bill of rights de la UE y tratado de derechos a los efectos del art. 10.2 CE, se expresa con nitidez en la LO $1 / 2008$, de 30 de julio, mediante la cual se ratifica el tratado de Lisboa conforme al procedimiento previsto por el art. $93 \mathrm{CE}$. Dice con toda claridad el último párrafo de la Exposición de Motivos:

«Por último debe resaltarse con especial énfasis que, según el Tratado de Lisboa, la Unión reconoce los derechos, libertades y principios enunciados en la Carta de los Derechos Fundamentales de 7 de diciembre de 2000, tal como fue adaptada el 12 de diciembre de 2007 en Estrasburgo, la cual, proclama, tendrá el mismo valor jurídico que los Tratados. Se trata de un avance de considerable valor político, además de jurídico, en el proceso de construcción de la Unión y de la ciudadanía europea. Por ello, y porque se considera conveniente desde el punto de vista de la transparencia y de la proximidad al ciudadano, se reproduce en el artículo segundo de esta Ley Orgánica el texto íntegro de la citada Carta, tal y como ha sido publicado en el "Diario Oficial de la Unión Europea" de 14 de diciembre de 2007 (2007/C 303/01).»

Para, a continuación, sostener en el artículo 2 de la citada LO:

«A tenor de lo dispuesto en el párrafo segundo del artículo 10 de la Constitución española y en el apartado 8 del artículo 1 del Tratado de Lisboa, las normas relativas a los derechos fundamentales y a las libertades que la Constitución reconoce se interpretarán también de conformidad con lo dispuesto en la Carta de los Derechos Fundamentales publicada en el «Diario Oficial de la Unión Europea» de 14 de diciembre de 2007, cuyo texto íntegro se reproduce a continuación».

Por tanto la CDFUE es, sin duda, un texto internacional de derechos y como tal ha de ser aplicado por el juez español. Esto es, con la eficacia y la virtualidad conferida a este tipo de fuente normativa en virtud de la Constitución. En este sentido la CDFUE no presentaría ninguna diferencia ni, por ende, ninguna

3 Como es sabido la CDFUE no es incorporada como tratado constitutivo de la UE, sino que es el propio TUE el que le reconoce «el mismo valor jurídico de los tratados», pero no su consideración en sí misma como tal. Véase art. 6.1 TUE. 
dificultad nueva para el juez nacional que ha de aplicarla exactamente igual que el resto de textos declarativos de derechos de ámbito internacional ratificados por España.

Ahora bien, también es la Carta de Derechos de la UE y, por tanto, se aplica exactamente igual y de acuerdo con los mismos principios con los que se aplica el Derecho de la UE. Este es un punto esencial que quizás no ha sido bien comprendido. El hecho de que estemos hablando de derechos fundamentales no cambia, al menos no en la comprensión de la Carta del TJUE, en absoluto ninguno de los principios básicos de aplicación del Derecho de la UE. Y aquí el punto de partida es evidente: el Derecho de la UE se aplica, exclusivamente, allí donde ésta tiene competencias y las ha ejercido. Por lo tanto la Carta se aplicará al citado Derecho de la UE y no más allá. La dicción del art. 51.1 de la CDFUE desde esta perspectiva resulta lógica: «Las disposiciones de la presente Carta están dirigidas a las instituciones, órganos y organismos de la Unión, dentro del respeto al principio de subsidiariedad, así como a los Estados miembros únicamente cuando apliquen el derecho de la Unión...»

Y obviamente, párrafo 2, reiterando lo ya previsto en el artículo 6.1 TUE, «La presente Carta no amplia el ámbito de aplicación del Derecho de la Unión más allá de las competencias de la Unión, ni crea ninguna competencia o misión nuevas para la Unión, ni modifica las competencias y misiones definidas en los tratados».

Dicho en otros términos el juez nacional sólo ha de aplicar la Carta de Derechos Fundamentales si está aplicando Derecho de la Unión, esto es, como se ha dicho con frecuencia en la jurisprudencia del TJUE de manera muy gráfica, si existe un vínculo o conexión con el Derecho de la Unión en la actuación del juez nacional.

En definitiva, pues, cuando estamos aplicando derecho de la Unión, cuando existe ese vínculo o conexión con dicho Derecho, el juez ha de aplicar la Carta. Y ha de hacerlo exactamente igual que el resto del Derecho de la Unión (y aquí obviamente el principio de autonomía del ordenamiento jurídico de la UE es el insoslayable punto de partida con los corolarios lógicos expresados por los principios de primacía y efecto directo así como, en alguna medida, el resto de principios básicos del Derecho de la UE). Fuera de ese ámbito de aplicación, para el juez español y por mandato de la LO 1/2008 y, según el TC, de la Constitución, el juez español habrá de aplicarla como un tratado de derechos fundamentales.

Lo cierto es que, en mi opinión, este punto de partida no ha sido totalmente correcto por no reflejar coherentemente la posición constitucional de la Carta desde el punto de vista nacional. A mi juicio, desde un punto de vista sustancial y formal la Carta no es un tratado de derechos. Es el bill of rights de la Unión Europea. Es diferente. Ciertamente no es el bill of rights de otro Estado, ajeno por ello al ordenamiento jurídico español. Pero tampoco es un tratado de mínimos sobre el contenido de los derechos que ha de respetar el intérprete y aplicador del derecho español. Creo que aquí hay un cierto error de origen que ya ha conducido a algún resultado indeseable como podrá observarse al finalizar la presente exposición. 
2. La existencia de vínculo con el Derecho de la UE es evidente cuando se está aplicando directamente Derecho de la UE o cuando se está aplicando una normativa nacional expresamente dirigida a trasponer Derecho de la UE, pero puede no ser tan clara en otras situaciones

Como se acaba de apuntar, la Carta es el texto normativo de referencia en materia de derechos cuando existe conexión con el derecho de la UE porque nos encontramos en su ámbito de aplicación. Esto no significa que el juez deba realizar un análisis competencial respecto a si la cuestión objeto del litigio entra dentro del ámbito de funciones atribuidas a la Unión. El juez nacional simplemente ha de comprobar si debe aplicar el Derecho de la UE al caso concreto que está conociendo.

En primer lugar, el juez estará en dicho ámbito si está aplicando directamente los tratados constitutivos de la UE. Esto, normalmente, será muy claro. Sin embargo, en ciertas ocasiones puede no resultar tan evidente. Especialmente cuando nos encontramos en el ámbito de las libertades comunitarias (libre circulación de bienes, personas, capitales o servicios) en los que cualquier medida que pudiera ser limitativa de su ejercicio supondría automáticamente entrar en el ámbito de aplicación del Derecho de la UE. Algo parecido puede decirse respecto a las normas reguladoras de la ciudadanía que dada su naturaleza a menudo horizontal generan dudas respecto a la concreta extensión de su ámbito de aplicación. En este tipo de casos deberá el juez tener en cuenta que el art. 52.2 CDFUE establece que «Los derechos reconocidos en la presente Carta que constituyen disposiciones de los Tratados se ejercerán en las condiciones y dentro de los límites determinados por éstos».

También deberá aplicarse la CDFUE como derecho de la UE en el caso de aplicación directa por el juez de principios generales de Derecho de la UE. Esto, evidentemente puede plantear problemas en cuanto tales principios pueden provocar una extensión clara a ámbitos a priori no previstos (el ejemplo en España es claro en lo referido a la extensión al ámbito procesal de los derechos de la Carta como consecuencia del principio general de protección máxima a los consumidores) o bien por tener naturaleza horizontal y, con ello, susceptibles de afectar a muchas y variadas cuestiones; el ejemplo más claro podría ser sin duda, dados los problemas generados por las Sentencias Mangold, Küküicdeveci y recientemente, Dansk Institut, la prohibición de discriminación por razón de edad ${ }^{4}$.

Estaremos, obviamente, también en el ámbito de aplicación del Derecho de la Unión, cuando el juez haya de aplicar al caso directamente una norma de derecho derivado, sean estas contenidas en Reglamentos, Directivas o Decisiones o

4 SSTJUE Mangold, de 22 de noviembre de 2005, C144-04; Kükürdeveci, de 19 de enero de 2010; C-555/07; Dansk Industri, de 19 de abril de 2016, C-441/14. 
cualquier otra fuente normativa susceptible de generar efecto directo en la actuación de los tribunales (esto es normas suficientemente precisas e incondicionadas $\mathrm{y}$, en el caso de las directivas, en las relaciones verticales).

Por último, nos encontraremos dentro del ámbito de aplicación del Derecho de la UE, y por tanto será aplicable al caso la CDFUE, cuando el juez haya de utilizar para resolver el caso cualquier normativa nacional dictada para cumplir con las obligaciones o garantizar los derechos contenidos en el Derecho de la UE. De este modo tanto las normas mínimas necesarias para garantizar el cumplimiento de Reglamentos o Decisiones, como las normas de trasposición de Directivas, los actos administrativos (generales o no) dictados en aplicación de normas europeas o cualquier otra norma o acto estatal en aplicación de Derecho de la UE deberá ser valorado por el juez desde la óptica de la CDFUE.

En definitiva, por tanto, la CDFUE es aplicable tanto cuando el juez aplica directamente Derecho de la Unión, como cuando aplica derecho nacional que supone desarrollo, trasposición o concreción del Derecho de la Unión. Y esta segunda parte de la afirmación no resulta, como es evidente, tan sencilla ni tan clara para el juez nacional.

\section{La aplicación judicial de normativa nacional no directamente dirigida} al desarrollo o trasposición de Derecho de la UE puede tener vínculo comunitario si, en las circunstancias concretas del caso, constituye el vehículo para garantizar el cumplimiento y la efectividad de derechos y obligaciones contenidas en las normas del Derecho de la UE

La normativa nacional en aplicación y desarrollo del Derecho de la UE puede entenderse en un sentido amplio y en un sentido estricto. En sentido estricto sólo la normativa específica y concretamente dirigida a la aplicación del derecho de la UE sería la que constituiría un vínculo con dicho Derecho y con ello atraería la CDFUE hacia su aplicación por el juez nacional. Junto a esta interpretación, también podría entenderse que se considera, además de la específicamente dirigida a ello, normativa nacional en aplicación de Derecho de la Unión a toda norma o acto jurídico que sirve para garantizar el respeto a los derechos o el cumplimiento de las obligaciones derivadas del Derecho de la Unión.

La STJUE 5 en el asunto Fransson resolvió la cuestión con meridiana claridad. Aunque la norma nacional no se refiera a ninguna norma europea, aunque no

5 Vid Aklagaren y Hans Äkerberg Fransson (STJUE de 26 de febrero de 2013, C-617/10) resolviendo cuestión prejudicial planteada por un tribunal sueco respecto a la posible violación del principio non bis in idem como consecuencia de la doble sanción (tributaria y penal) posible en un caso de fraude de IVA. La normativa nacional no se dirigía a aplicar en concreto Derecho de la UE, pero era el instrumento normativo nacional 
haya sido dictada para ejecutar, desarrollar o transponer una norma europea, incluso aunque su finalidad fuera, en un principio otra muy diferente, si la norma sirve para hacer efectivo un derecho o asegurar el cumplimiento de una obligación derivada de Derecho de la Unión, dicha norma será considerada desarrollo de Derecho de la Unión y con ello exigirá la aplicación al caso de la CDFUE. Como decíamos Fransson es paradigmático pues considera dentro del ámbito de aplicación del derecho de la UE a la normativa penal reguladora del fraude de IVA porque, aun siendo una norma no dirigida a ejecutar en concreto ninguna norma europea, es la norma reguladora de las sanciones imponibles a quienes incumplan las obligaciones de un impuesto de origen y regulación Europea y cuya defraudación afecta a la hacienda europea. Por el contrario, en otros supuestos, en los que la norma nacional nada tenga que ver con el objetivo buscado por las normas europeas, no se apreciará vínculo con el Derecho de la UE y por ello no será de aplicación la $\mathrm{CDFUE}^{6}$.

De este modo, cualquier norma nacional que sea utilizada como vehículo para canalizar el cumplimiento de normas europeas (esto es para asegurar el respeto a los derechos y obligaciones derivados del derecho de la UE) no sólo deberá cumplir ya los requisitos derivados de la actuación de los principios de equivalencia y eficacia tradicionalmente exigidos a este tipo de normas. Además, deberán respetar los derechos fundamentales tal y como están definidos en la CDFUE y cómo se vayan concretando en la práctica por parte del TJUE.

Este planteamiento tendrá una indudable relevancia en el ámbito procesal. Efectivamente, el Derecho procesal era un sector del ordenamiento en el que el Derecho de la UE no tenía apenas competencias (excepto en algunos supuestos concretos derivados del espacio de seguridad y justicia) y ejemplo de actuación del principio de autonomía institucional. Correspondía pues al Estado miembro regular las normas procesales con toda libertad si bien tal regulación habría de garantizar que los derechos y obligaciones derivados del Derecho de la UE recibieran un trato procesal equivalente a aquellos derivados solo del derecho nacional y fueran eficaces en la defensa del cumplimiento de tales derechos y obligaciones. Ahora, además, deberán respetar los derechos de los arts. 47 y 48 de la CDFUE. Sobre esta cuestión volveremos más adelante.

dirigido a perseguir las infracciones tributarias en materia de IVA por lo que el TJUE lo consideró normativa dentro del ámbito de aplicación del Derecho de la UE a los efectos del art. 51 de la CDFUE y por ello entró en el fondo del asunto.

6 En tal sentido puede consultarse Gueye y Salmerón Sánchez (STJUE, de 11 de septiembre de 2011, C-483/09 y C-1/10) resolviendo una cuestión prejudicial planteada por la Audiencia Provincial de Tarragona que pretendía se aplicara la CDFUE a la normativa española que no tenía en cuenta la opinión de la víctima de delitos de violencia de género a la hora de establecer la pena de alejamiento incluso cuando dicha víctima decidiera convivir de nuevo con su agresor. Para el TJUE la regulación de la UE mediante Decisión Marco de la cuestión era garantizar el Estatuto de la víctima, mientras que la normativa española respondía a un objetivo de política criminal sustantiva que no es objeto de competencia de la UE. 


\section{EFECTOS DE LA APLICACIÓN DE LA CARTA SOBRE LOS DERECHOS FUNDAMENTALES UTILIZADOS POR EL JUEZ}

\section{La apreciación de vínculo con el Derecho de la Unión supone, en principio, el desplazamiento de los derechos fundamentales reconocidos en la Constitución por los reconocidos en la CDFUE y la consiguiente sujeción a la jurisprudencia sobre la materia emanada del TJUE y no del TC}

Una vez decidido que nos encontramos en el ámbito de aplicación del Derecho de la Unión, la CDFUE se impone al juez nacional en, exactamente, los mismos términos que el resto del Derecho de la Unión. Y en tal sentido no es ocioso recordar que tal imposición se asienta en los principios clásicos de tal Derecho como son la autonomía del Derecho de la Unión con su consecuente unidad en su interpretación y aplicación, primacía, efecto directo y complementado por los principios de equivalencia, eficacia y responsabilidad del Estado por su incumplimiento (incluido el incumplimiento judicial).

Ello supone que en principio el juez nacional está obligado a eliminar todo obstáculo que pueda oponerse a la aplicación de la CDFUE, incluidos los de origen constitucional. Por tanto, en caso de que se produzca una contradicción entre derecho interno y CDFUE, el juez estará obligado a interpretar éste de manera conforme con aquélla y, en caso de que la contradicción resultara insalvable, deberá desplazar la aplicación de la norma interna.

En el caso de la CDFUE esto implicará que si el conflicto se produce entre el Derecho de la Unión, en concreto de la Carta, y uno de los derechos fundamentales reconocidos en la Constitución, deberá interpretarse éste de acuerdo con la CDFUE y en caso de ser imposible una interpretación conforme deberá desplazarse su aplicación a favor del contenido en la norma europea.

Del mismo modo que se produce el desplazamiento en los textos a favor del Derecho de la Unión, se producirá el desplazamiento en la interpretación de los derechos y por tanto en el alcance de la jurisprudencia de sus respectivos intérpretes. Cuando nos encontremos en el ámbito de aplicación del Derecho de la Unión, la jurisprudencia, en principio, preferente en su aplicación será la del TJUE y no la del Tribunal Constitucional (que, por otra parte, será la de aplicación, en los términos que se desarrollan más adelante, en el caso de los derechos fundamentales reconocidos en la Constitución).

Cabe, sin embargo, realizar dos precisiones. Atañe la primera a que la propia CDFUE limita la eficacia vinculante para el juez de algunas de sus previsiones. Así, el art. 52.5 de la CDFUE establece: «Las disposiciones de la presente Carta que contengan principios podrán aplicarse mediante actos legislativos y ejecutivos adoptados por las instituciones, órganos y organismos de la Unión, en el ejercicio de sus competencias respectivas. Sólo podrán alegarse ante un órgano jurisdiccional en lo que se refiera a la interpretación y control de la legalidad de 
dichos actos». Por tanto, en el caso de las previsiones contenidas en la CDFUE que no sean verdaderos derechos sino principios (aunque la propia CDFUE no los diferencie con claridad) el desplazamiento interno de los derechos nacionales por parte del juez no se producirá, prima facie, excepto cuando ello fuera una consecuencia de la interpretación de actos de la UE que pudieran provocar efectos limitativos sobre los derechos nacionales.

Se refiere la segunda, y más importante, a que a lo largo del texto hemos utilizado la palabra desplazamiento de las normas internas de derechos fundamentales y en ningún caso de nulidad o invalidez de las mismas. Y ello porque estas podrán seguir estando plenamente vigentes, primero, cuando no estemos en el ámbito de aplicación del derecho de la Unión y, segundo, cuando, no siendo coincidentes con la propia CDFUE, la aplicación unitaria y uniforme del Derecho de la Unión no se vea obstaculizada. Lo mismo habrá de decirse respecto a la jurisprudencia constitucional dictada en materia de derechos fundamentales, que sólo devendrá inaplicable para el juez cuando se encuentre dentro del ámbito de aplicación del Derecho de la Unión y simultáneamente obstaculice la aplicación uniforme de este. Estas afirmaciones nos llevan a la siguiente conclusión.

\section{El desplazamiento de los derechos fundamentales reconocidos en la CE} puede no ser total si el Derecho de la Unión permite a los Estados margen de maniobra para otorgar una mayor protección a los derechos conforme a sus constituciones, teniendo siempre en cuenta que con ello no se puede poner en peligro la eficacia del Derecho de la UE (y en particular la unidad en la aplicación de éste)

En principio la CDFUE no impide que los jueces nacionales apliquen estándares superiores de protección de derechos si así lo exige la constitución nacional, al igual que ocurre con los derechos reconocidos en el CEDH. Pero no cabe olvidar que nos encontramos en un sistema de relaciones entre ordenamientos jurídicos muy diferente al que rige las relaciones entre el derecho nacional y el CEDH. Por ello, el principio de mayor protección del derecho ha de tener en cuenta dos elementos.

Por una parte, el criterio de mayor protección es a menudo equívoco. En la interpretación de los derechos fundamentales nos encontramos frecuentemente en situaciones en que el principal problema deriva de la existencia de un posible conflicto respecto al contenido y alcance de dos derechos fundamentales. En tales situaciones dar mayor protección a uno de los derechos en conflicto supone, automática e inevitablemente, dar menor protección al otro derecho concurrente. Por ello, a menudo, no estará tan clara la aplicación de este criterio con carácter general.

Por la otra, y más importante, conferir mayor protección a un derecho sólo es aceptable si está permitido por el propio Derecho de la Unión, esto es, si se encuentra dentro de las posibilidades de actuación del Estado en el margen de 
maniobra dejado por dicho Derecho. La definición del principio de primacía en virtud del cual no puede oponerse ningún obstáculo (ni siquiera constitucional) a la aplicación del Derecho de la UE sigue vigente. Por ello, estará prohibida la aplicación de estándares superiores en la protección de derechos como consecuencia de un mandato interno (incluso derivado de la constitución) si ello implica cuestionar la aplicación y eficacia del derecho de la Unión o su interpretación uniforme en todo el territorio europeo. En tal sentido la sentencia del $\mathrm{TJUE}^{7}$ a la cuestión prejudicial planteada por el Tribunal Constitucional español en el conocido asunto Melloni no es más que la aplicación en concreto, en el campo de los derechos fundamentales, del principio de primacía del Derecho de la Unión y de su consideración como un ordenamiento jurídico autónomo formulado hace ya casi cincuenta años.

Estas afirmaciones nos permiten, a su vez, apuntar cuál es, a nuestro juicio, la mejor solución práctica a uno de los problemas que más parecen haber preocupado a los comentaristas de la carta: el de la doble prejudicialidad y el establecimiento de normas de prioridad al respecto. Este problema, resumiendo las diferentes cuestiones suscitadas, viene a plantear qué ha de hacer el juez nacional en los supuestos de que aprecie la posible contradicción de una norma interna de rango legal con los derechos fundamentales tanto de la CDFUE como de la Constitución nacional. ¿A qué instancia hay que acudir: al TJUE a través de la Cuestión Prejudicial o al TC a través de la Cuestión de Inconstitucionalidad?. Pregunta que será tanto más importante si, como ha ocurrido en algunos de los ordenamientos europeos, el legislador nacional ha establecido la prioridad de la cuestión nacional a la europea y a la que el asunto ${ }^{8}$ Melki no ofreció una solución tan concluyente como la que habrían deseado los jueces europeos que conocen de este tipo de casos. La respuesta, a estas alturas del decálogo, en la práctica no parece complicada. La pregunta ha de dirigirse al tribunal que corresponda según estemos o no en el ámbito de aplicación del Derecho de la UE. Si lo estamos, al TJUE y si no lo estamos al TC. Pero, ¿que deberá hacer el juez en los casos en los que hay margen de maniobra para el Estado o no está claro si estamos o no dentro del ámbito de aplicación del Derecho de la Unión?. La respuesta es, de nuevo, clara, debe ser prioritaria la cuestión prejudicial porque el intérprete del Derecho de la UE es el TJUE. Es este Tribunal quien está encargado de salvaguardar la autonomía y unidad en la interpretación y aplicación del Derecho de la UE. De este modo el TJUE es el único competente para determinar cuestiones que, en su caso, necesitará el TC nacional para poder decidir un caso de este tipo sometido a su consideración.

7 Nos referimos a la conocida saga Melloni compuesta por el ATC 86/2101 planteando cuestión prejudicial, la STJUE Stefano Melloni, de 26 de febrero de 2013, C-399/11 resolviendo la citada cuestión prejudicial y la STC 26/2014, de 13 de febrero de 2014, que acabó cerrando el caso

8 STJUE (Gran Sala) de 22 de junio de 2010. Asuntos Aziz Melki (C-188/10) y Sélim Abdeli (C-189/10). 
El TJUE deberá determinar, en primer lugar, si es de aplicación la CDFUE; y si lo es, deberá establecer, en segundo lugar, si la normativa europea con la que se establece la conexión comunitaria respeta la CDFUE y si lo hace, tendrá que concretar, en tercer lugar, si la normativa europea deja margen de maniobra para que los Estados establezcan mayor protección y, en cuarto y último lugar, hasta dónde alcanza el margen de apreciación dentro del que puede moverse la normativa nacional. Y estas decisiones, primero, corresponden en exclusiva al TJUE y, segundo, son necesarias para establecer los límites dentro de los que el Juez constitucional nacional puede interpretar su derecho a la hora de, eventualmente, declarar contraria a un derecho constitucional una normativa nacional en aplicación de Derecho de la UE que es, sin embargo, conforme con el citado Derecho y muy singularmente con la CDFUE.

De este modo existe una prioridad lógica desde el punto de vista aplicativo a favor del planteamiento de la Cuestión prejudicial sobre la Cuestión de inconstitucionalidad.

Recientemente el Tribunal Constitucional, mediante el ATC 168/2016, ha reconocido con carácter general que los jueces han de plantear la cuestión prejudicial antes que la cuestión de inconstitucionalidad. Sin embargo, los argumentos utilizados por el Tribunal Constitucional han sido distintos y, a nuestro juicio, habrían sido válidos también para justificar una eventual prioridad de la cuestión prejudicial ${ }^{9}$. Sea como fuere, la solución final propuesta es la más razonable desde un punto de vista práctico porque permitirá al TJUE determinar si efectivamente es de aplicación la CDFUE y cuál es el margen de maniobra dejado a las autoridades judiciales españolas para, en su caso, aplicar un estándar de protección de los derechos más amplio si así lo prevé la Constitución.

El asunto Melloni dejó claro el funcionamiento de este esquema. La normativa aplicable era la CDFUE porque nos encontrábamos en el ámbito de aplicación del Derecho de la Unión (la Decisión marco sobre la orden de detención y entrega). Que la normativa europea no contemplara una excepción a la entrega del recurrente a otro país miembro de la Unión para ser juzgado, cuando ya había sido condenado en ausencia, no era, a juicio del TJUE, lesiva de ningún derecho fundamental reconocido en la CDFUE. Y, por último, la normativa de la UE no dejaba ningún margen al Estado para oponer excepciones distintas a las

9 El argumento básico esgrimido en el citado Auto, dictado por el Pleno, es que es necesaria la cuestión prejudicial porque hasta que el TJUE no se pronuncie no se sabrá si la norma legal cuestionada es aplicable o no al caso lo que, como es conocido, constituye un requisito previo para el planteamiento de la cuestión de inconstitucionalidad. El problema es que este argumento es igualmente utilizable, a la inversa, respecto a la cuestión prejudicial. En esta se cuestiona ante el TJUE si el Derecho de la Unión permite o no la aplicación de una concreta regla al caso. Si esta regla fuera inconstitucional no sería aplicable al caso y, por tanto, tampoco podría ser objeto de la Cuestión prejudicial. En ambos casos se requiere cuestionar sobre la norma aplicable al caso y, precisamente, dicha aplicabilidad depende de que sea conforme con la Constitución y con el Derecho de la Unión por lo que el argumento no establece ninguna prioridad lógica. 
previstas en la Decisión marco porque ello hacía ineficaz la normativa europea y rompía su uniforme aplicación al hacerla depender del cumplimiento de condiciones nacionales heterogéneas. Estas tres cuestiones básicas (aplicabilidad de la CDFUE, conformidad de la Decisión Marco con la CDFUE e inexistencia de margen de apreciación dejado a las autoridades nacionales) corresponden determinarlas al TJUE y no a los tribunales nacionales. Una vez establecidas por el órgano judicial competente, al Tribunal Constitucional no le quedaba margen de libertad y, en todo caso, debía concluir el desplazamiento de las normas nacionales de derechos fundamentales. Determinar cuál sea el grado de desplazamiento y, por tanto, la intensidad de la reinterpretación de los derechos fundamentales nacionales a la luz de tales restricciones es, ahora sí, competencia del juez (constitucional) nacional ${ }^{10}$.

\section{Desde un punto de vista práctico, la aplicación de la CDFUE no supone} una revolución en los contenidos de los derechos puesto que no existirán diferencias importantes en la configuración de los mismos, sino, sobre todo, especialidades y cambios de matices. Además el CEDH opera como elemento unificador de mínimos en todos los Estados de la UE

Esta es la que podemos llamar la «conclusión tranquilizadora» para los jueces y magistrados que han de aplicar la Carta. En efecto, la interacción producida entre el orden jurídico de la UE, los órdenes jurídicos nacionales y el derivado del Consejo de Europa en los últimos 50 años ha provocado una fuerte homogeneidad sustancial de base en materia de derechos fundamentales y un verdadero derecho común europeo de los derechos humanos.

En particular ha de destacarse cómo en los diferentes textos y en la propia jurisprudencia de los tres tribunales (TJUE, TEDH y TC) se pueden encontrar los puntos de conexión que han hecho posible una construcción razonablemente armónica de los tres ordenamientos hasta constituir un único sistema de derechos aplicable por el juez. Así los artículos art. 10.2 CE; arts 52 y 53 de la CDFUE y la acción de los principios de subsidiariedad y margen de apreciación nacional, en el caso del CEDH, han permitido que casi siempre se encontraran soluciones mutuamente aceptables para todos los órdenes jurídicos aplicables que ofrecen una salida relativamente sencilla para el aplicador judicial de los derechos fundamentales. En los pocos casos en los que tal armonización no era

10 Como es bien sabido, el TC español (STC 26/2014) optó por aplicar la decisión del TJUE en interpretación de la CDFUE en los términos del art. 10.2 CE y con ello procedió a reinterpretar la eficacia ad extra del art. 24 CE de acuerdo con el TJUE, pero no sólo para los casos sometidos a Derecho de la Unión, sino para todos los casos de entrega, estuvieran o no sometidos a dicho Derecho. Con ello no solo se redujo el ámbito de protección del derecho a la tutela judicial antes reconocido a los sujetos de una orden de detención y entrega europea sino a toda persona reclamada por un tercer Estado. 
posible (bien por condenas del TEDH a España, bien por incompatibilidad entre los derechos constitucionales y los de la Carta — hasta ahora sólo el asunto Melloni-) las cuestiones se han resuelto con las pertinentes modificaciones legislativas o de la interpretación judicial de los derechos mediante un, en ocasiones formal y en otras informal, eficiente diálogo entre los principales tribunales europeos.

De este modo, en la práctica será muy infrecuente que se produzcan problemas graves de compatibilidad entre la forma de definir y entender los derechos entre los distintos ordenamientos jurídicos. Y allí donde se produzcan deberemos tener en cuenta que esa homogeneidad sustancial básica unida a los márgenes de apreciación reconocidos a los jueces nacionales permitirán, con bastante facilidad, encontrar interpretaciones conformes.

En particular para el juez nacional aplicando la CDFUE será fundamental entender que en principio la Carta siempre habrá de respetar como contenido mínimo el CEDH y tener en cuenta para interpretar sus derechos la jurisprudencia del TEDH. Y esa doble obligación está presente también en los derechos nacionales. De este modo ya hay un sustrato común compartido entre Carta y derechos nacionales (de geometría variable según los derechos, eso sí) que permite afirmar que en la práctica no existirán grandes diferencias entre aplicar la CDFUE y la Constitución de modo que el juez podrá seguir actuando, en gran medida, igual que hasta ahora.

Y a ello no obsta el que la UE todavía no sea parte del sistema del CEDH o que el Dictamen ${ }^{11}$ del TJUE sobre el proyecto de tratado de adhesión a la Convención fuera negativo. Efectivamente, como bien recuerda el artículo 52.3 de la CDFUE en la medida en que ésta reconozca derechos contenidos en el CEDH su «sentido y alcance serán iguales» pudiendo, eso sí, la carta reconocer «una protección más extensa». Previsión esta, por otra parte, que no es más que una concreción del art. 6.3 TUE.

En este mismo sentido la Sentencia del TJUE ${ }^{12}$ en el asunto J.N ha venido a concretar esta obligación. Recuerda el Tribunal que a pesar del art. 52.3 CDFUE y de que los derechos reconocidos en el CEDH forman parte del Derecho de la Unión como principios generales conforme al art. 6.3 y que su contenido y alcance debe ser el mismo que el de la CDFUE, lo cierto es que como tal no forma parte del ordenamiento jurídico de la UE en tanto que no se ha producido la adhesión al Convenio. Por ello, todo juicio de conformidad con los derechos debe basarse en la CDFUE; si bien habrá de tenerse en cuenta el CEDH para interpretar la Carta. De este modo, ya en el caso, el TJUE procede a analizar la jurisprudencia del TEDH sobre la cuestión suscitada y a concluir que no hubo infracción ni del CEDH ni, por ende, de la CDFUE.

11 Dictamen 2/13 del TJUE, de 18 de diciembre de 2014.

12 STJUE, J.N, de 15 de febrero de 2016, C-601/15. 


\section{CAMBIOS EN LA POSICIÓN DEL JUEZ COMO CONSECUENCIA DE LA VIGENCIA DE LA CDFUE}

1. El uso del CEDH (y de la jurisprudencia del TEDH) por parte de los tribunales españoles cuando se encuentren en el ámbito de aplicación de la CDFUE no variará sustancialmente respecto a la situación existente antes de la entrada en vigor de la CDFUE, ni respecto a la funcionalidad del CEDH en la interpretación de los derechos contenidos en la CE. Sin embargo, ha de tenerse en cuenta que si una norma de derecho de la UE contradice el CEDH casi con toda seguridad lesionará también la CDFUE

A la vista de las anteriores conclusiones, es claro que el juez español juzgando como juez europeo deberá seguir utilizando el CEDH y la jurisprudencia del TEDH como el contenido mínimo reconocido a los derechos fundamentales que ha de proteger en ejercicio de su función jurisdiccional, tanto si aplica la CDFUE como si aplica la Constitución.

Así, del mismo modo que ocurre con el derecho nacional, si una disposición o acto contradice la jurisprudencia del TEDH y por ello al CEDH, lo habitual es que esa disposición o acto contradiga igualmente la carta (nacional o europea) aplicable en función de que exista o no conexión con el derecho UE. Contradicción que el juez deberá resolver con interpretación conforme de la norma aplicable; con su inaplicación (si tuviera potestad para ello) o con la interposición bien de una Cuestión Prejudicial (sea de validez si la duda se suscita respecto a norma europea, sea de interpretación si la cuestión se suscita respecto a la norma o práctica nacional en aplicación de Derecho de la Unión), bien de una Cuestión de inconstitucionalidad (si la duda se suscita respecto a una ley nacional en el margen de maniobra dejado por el Derecho de la Unión o bien en un asunto en que tal Derecho no es aplicable).

El funcionamiento del sistema se ha ejemplificado con claridad en los asuntos Melloni, por una parte, y N.S y Aranyosi E Caldararu, por la otra.

En el ya citado asunto Melloni, el Tribunal Constitucional español vino a preguntar, por una parte, si la Decisión Marco no contradecía la CDFUE al no prever excepciones a la entrega de una persona reclamada por otro país de la UE vinculadas a su condena en ausencia. La pregunta tenía sentido en la medida en que, de acuerdo a la jurisprudencia nacional previa, tal cosa resultaría una violación del contenido conferido en España al derecho a la tutela judicial efectiva. En caso de que el TJUE considerara, como así fue, que no existía tal violación del derecho por ese motivo de acuerdo con la CDFUE, el TC plantearía si podía oponer a la aplicación de la Decisión la existencia del derecho fundamental reconocido constitucionalmente. A esta segunda cuestión la respuesta del TJUE será una negativa tajante porque lo contrario rompe la unidad en la aplicación del derecho de la Unión en este punto que se asienta en el principio de confianza 
mutua respecto al respeto de los derechos en todos los países de parte del espacio único de seguridad y justicia. Como ya se ha dicho más arriba, esta no es más que la aplicación, en el campo de los derechos, del principio de primacía.

Ahora bien, la situación no será la misma cuando el problema no derive de la posible violación de un derecho constitucionalmente reconocido, sino de la posible violación de uno de los derechos contenidos en el CEDH que, como se ha dicho, han de ser tenidos en cuenta para determinar el alcance de los derechos reconocidos en la CDFUE. Los asuntos N.S y Aranyosi $\mathcal{E}$ Caldararu constituyen buenos ejemplos de cómo han de actuar los jueces nacionales en este tipo de supuestos.

En el caso N.S ${ }^{13}$. el supuesto planteado era relativo a la expulsión de un solicitante de asilo en Reino Unido para que su petición fuera tramitada por el Estado competente según la normativa entonces vigente en materia de asilo. En concreto se debía expulsar al recurrente a Grecia por ser el Estado el que ingresó en la Unión Europea. El caso tenía un precedente muy interesante en un supuesto muy similar resuelto por el TEDH en el asunto MSS contra Bélgica y Grecia ${ }^{14}$ apenas unos meses antes. En este segundo caso el TEDH había condenado a Bélgica y Grecia en un supuesto muy similar en el que el recurrente, M.S.S., había solicitado asilo en Bélgica pero fue expulsado a Grecia por ser su país de entrada a la Unión. El TEDH consideró que con ello se violaba el artículo 3 del CEDH puesto que la situación de los solicitantes de asilo en Grecia generaba tratos degradantes para los afectados. La condena no sólo afectó a Grecia, sino también a Bélgica por la entrega del recurrente porque, aún tratándose de ejecución de Derecho de la UE, el Estado tenía margen de maniobra para haber decidido tramitar por sí mismo la solicitud de asilo sin necesidad de entregar al recurrente ${ }^{15}$. En el asunto N.S. se debe resolver una cuestión prejudicial planteada por la Court of Appeal de Inglaterra y Gales en la que se preguntaba si debía expulsar al recurrente a pesar del riesgo de lesión a su derecho a no sufrir tratos inhumanos o degradantes. La respuesta del TJUE, apoyándose expresamente en la previa sentencia del TEDH, es que no debía procederse a la expulsión en la medida en que eso suponía una violación de los derechos del recurrente de acuerdo con el CEDH.

En el asunto Aranyosi \& Caldararu el TJUE da un paso más puesto que a diferencia del supuesto planteado en N.S. el Derecho de la Unión no dejaba, en

13 STJUE N.S v Secretary of State for the Home Department, de 21 de diciembre de 2011, C-411/10.

14 STEDH M.S.S. c. Bélgica y Grecia, de 21 de enero de 2011.

15 Debe notarse que el TEDH no es competente, en principio, para revisar los actos de los Estados miembros del Convenio cuando aplican Derecho de la UE en cuanto la UE no es miembro del sistema del Convenio, excepto si no existiera una protección equivalente en el ámbito de la propia UE tal y como se establece en la jurisprudencia a partir del asunto Bosphorus Airways c. Irlanda, de 30 de junio de 2005 . El caso era diferente porque aquí el Derecho de la UE permitía margen de maniobra al Estado (Bélgica) que podía evitar la lesión al derecho del CEDH a la vez que cumplía con el Derecho de la UE simplemente asumiendo la tramitación de la solicitud de asilo. 
principio, margen de maniobra al Estado miembro para incumplir la norma de la Unión. En ambos casos el problema se suscita con la ejecución de una orden de entrega a Hungría y a Rumanía. Al juez alemán que plantea la cuestión, se le suscita el problema de que en fechas previas el TEDH había declarado en sendas sentencias que las condiciones de los centros penitenciarios a los que podían ser enviados los recurrentes no cumplían las condiciones mínimas para garantizar el derecho a no sufrir tratos inhumanos o degradantes reconocido en el art. $3 \mathrm{CEDH}^{16}$. La respuesta en estos casos del TJUE es claramente diferente a la conferida al TC español en Melloni. Efectivamente, aunque la Decisión Marco no prevé claramente estas excepciones, el TJUE considera que en este tipo de supuestos el juez nacional no puede permitir que se lesione el art. 4 de la CDFUE que ha de entenderse igual que el art. 3 del CEDH y por ello, el juez nacional habrá de pedir seguridades a los Estados receptores de la persona entregada respecto al respeto de sus derechos y, en caso de no obtenerlas, incluso no efectuar la entrega.

Puede verse aquí claramente el distinto juego que tienen los derechos nacionales y los derechos del CEDH en la interpretación de la CDFUE. En el primer caso sólo serán utilizables si lo permite el Derecho de la UE. En el segundo caso, posiblemente una violación de los derechos del CEDH provocará una violación de la CDFUE y el juez nacional/europeo deberá actuar en consecuencia. De este modo deberá interpretar la normativa europea de modo que la lesión no se produzca (asunto N.S.) o incluso deberá inaplicarla en el caso si no fuera posible respetar los derechos (asunto Aranyosi). Y ello será especialmente claro si existe una previa sentencia del TEDH donde tal violación haya sido previamente declarada.

La interacción subsiguiente es bastante clara después de Aranyosi. Así, por ejemplo, si tenemos una solicitud de entrega de un ciudadano griego a la prisión de Diavata en Tesalónica, podremos paralizar la solicitud y pedir seguridades de que no va a recibir un trato degradantes, en violación del art. $3 \mathrm{CEDH}$, oponiéndonos, con ello, a la aplicación de la normativa Europea de detención y entrega porque el $\mathrm{TEDH}^{17}$ ha declarado que en esa cárcel se producen tratos inhumanos. Incluso, toda esta operación puede hacerla directamente el juez, sin necesidad de plantear cuestión prejudicial (cosa que no podría hacer el juez antes de Aranyosi).

Así, si con posterioridad se condena a otros Estados por violación de los derechos contenidos en el CEDH, el juez nacional tendrá una duda que justifica u obliga (según los casos) a plantear una cuestión prejudicial para que el TJUE,

16 Se trata de las SSTEDH Varga y otros c Hungría, de 10 de marzo de 2015 y varias sentencias contra Rumanía: Voicu c. Rumanía; Bujorean c. Rumanía, Mario Laurentiu Marin c Rumanía y Constantin Aurelian Burlacu c. Rumanía, todas ellas de 10 de junio de 2014.

17 SSTEDH Adiel y otros c. Grecia y Ppodakis y otros c. Grecia, de 26 de febrero de 2016. 
teniendo en cuenta el CEDH, decida si la aplicación de la norma europea, o de la norma nacional en aplicación de aquélla, respeta la $\mathrm{CDFUE}^{18}$.

Sea como fuere lo cierto es que el esquema está claro. A la aplicación de una norma de la UE se le pueden oponer los derechos contenidos en la Carta. También se le podrán oponer los derechos reconocidos en el CEDH en la medida en que lesionar esos derechos supondrá lesión también de la propia CDFUE. Sin embargo, solo se pueden oponer los derechos constitucionales nacionales cuando éstos otorgan mayor protección que los de la CDFUE y solo si con ello no se condiciona la unidad en la interpretación y aplicación del Derecho de la UE.

2. La aplicación de la CDFUE supone un cambio en la posición del juez nacional en la protección de los derechos fundamentales. En el ámbito de aplicación de la CDFUE y dada la estructura del poder judicial de la UE, el juez nacional es la pieza clave (casi única) en la garantía de esos derechos por lo que debe estar dispuesto a utilizar la cuestión prejudicial cuando los considere amenazados bien por el Derecho de la UE directamente, bien por las normas nacionales necesarias para su aplicación

Debe tenerse muy claramente en cuenta el distinto papel en la protección de los derechos que ha de tener el juez nacional en el sistema de protección de los derechos fundamentales según se encuentre en el ámbito de aplicación del derecho de la UE o no. En especial en lo que se refiere al control de normas de alcance general.

En el ámbito del derecho nacional ese papel es casi residual: la Cuestión de Inconstitucionalidad en el caso de la ley. Pero ese carácter residual tiene sentido si se vincula con el conjunto del sistema de protección de derechos creado por la Constitución. Efectivamente, los derechos de los ciudadanos están protegidos por un sistema en varias capas. Un control abstracto de la ley derivado de los recursos directos de inconstitucionalidad con un amplio número de sujetos legitimados. La posibilidad de impugnar los actos de aplicación de las normas ante los tribunales nacionales pudiendo ascender en la pirámide judicial y llegar, incluso, ante el TC en amparo quien, en el caso de que la lesión al derecho derivara directamente de la norma legal, podría autoplantearse una cuestión de inconstitucionalidad. Y la posibilidad de alegar la

18 El caso Aranyosi no resuelve sin embargo todas las cuestiones planteables. La citada sentencia del TJUE no es lo suficientemente clara respecto a si, por ejemplo, la reinterpretación de la normativa europea reguladora de la orden de entrega (que puede llegar incluso a justificar que la entrega no se produzca) será exigible siempre que el reclamado pueda ver lesionados sus derechos del CEDH o solo si lo que se lesiona es la prohibición de tratos degradantes. 
inconstitucionalidad de la ley en el curso de los procesos en los que sea fundamental para el fallo de modo que los tribunales ordinarios puedan plantear una cuestión de inconstitucionalidad.

En el caso de las normas de alcance general de la UE este sistema es mucho más débil. Y es más débil por el poco uso práctico de las acciones de nulidad contra normas de alcance general de la UE; por las limitaciones en la legitimación activa ante el TJUE y sobre todo por la inexistencia de ninguna forma de casación ante el TJUE. Dicho en otros términos, si el tribunal nacional no cuestiona la conformidad de una norma de Derecho de la UE por ser contraria a los derechos fundamentales reconocidos en la CDFUE, posiblemente nadie la cuestionará y el ciudadano nunca podrá acabar llevando su caso ante el TJUE. En este marco, el juez nacional se convierte en una pieza «imprescindible» en el control de conformidad con los derechos del Derecho de la UE, incluyendo dentro de ese concepto tanto el derecho propiamente de la UE, como el derecho nacional dictado en aplicación del derecho de la UE. El primero será cuestionable con el uso de la cuestión prejudicial de validez. El segundo será cuestionado, aunque sea indirectamente, con la cuestión prejudicial de interpretación. Pero lo importante es que si el juez no plantea esas cuestiones cuando existan dudas sobre la conformidad del Derecho aplicable con la CDFUE, el ciudadano no podrá nunca alcanzar al TJUE para que resuelva la cuestión. Si el juez nacional incumple su obligación de plantear cuestión prejudicial de validez si considera la norma europea contraria al derecho de la UE o la cuestión prejudicial de interpretación cuando contra su resolución no cabe recurso, el ciudadano tendrá unas posibilidades muy limitadas de asegurar sus propios derechos. Y además esas posibilidades limitadas no se verán complementadas por otras vías dada la inexistencia de casación o amparo ante el TJUE y el poco uso de los recursos de nulidad ante el TJUE tanto por el limitado número de legitimados, como por la naturaleza consoncional del proceso decisorio comunitario que aleja cualquier incentivo para impugnar normas cuyo contenido se ha contribuido a formular.

Resulta pues claro que los tribunales nacionales habrán de estar dispuestos a usar la cuestión prejudicial de validez cuando aprecien que pueda existir un problema de conformidad entre norma europea y CDFUE y la cuestión prejudicial de interpretación cuando aprecien que puede existir un problema de conformidad entre norma nacional dictada dentro del ámbito de aplicación del derecho de la UE y la CDFUE o cuando consideren que la aplicación al caso de la norma de la UE pueda suponer lesión al derecho.

La enorme diferencia que supone para el papel del juez radica en que si en el marco del derecho nacional español no se planteaba cuestión de inconstitucionalidad, el particular siempre podía llevar su caso y la violación del derecho en casación ante el TS y después (o si no se pudiera ante el TS) ante el TC y, en fin, ante el TEDH. Ahora esto ya no es tan claro. El TC no puede ser juez de la conformidad con la CDFUE del derecho derivado o del dictado en aplicación 
del Derecho de la UE; tampoco el TEDH es ni, en principio, puede ser juez de un derecho dictado por una organización internacional que no es parte del $\mathrm{CEDH}^{19}$.

Los asuntos M.S.S. y N.S. muestran con enorme elocuencia el problema. En, M.S.S las autoridades judiciales belgas aplicaron el Derecho de la UE y no se plantearon ningún problema (pese a ser alegado) de derechos fundamentales. El recurrente fue expulsado a Grecia dónde, a juicio del TEDH, sufrió tratos degradantes contrarios al art. 3 CEDH. De ahí derivó la condena a ambos Estados. En el supuesto de N.S. por el contrario, las autoridades judiciales británicas plantearon la pertinente cuestión prejudicial solicitando al TJUE una interpretación de la normativa europea conforme con los derechos. El TJUE ofreció esa interpretación que impidió la extradición del recurrente y, con ello, la vulneración de sus derechos. En el caso M.S.S. la violación del derecho se produjo. En el caso N.S. el tempestivo y correcto uso de la cuestión prejudicial permitió que sus derechos no se vieran violados.

\section{La negativa a utilizar la cuestión prejudicial para resolver una cuestión} de derechos fundamentales en el ámbito de aplicación de la CDFUE debe estar suficientemente motivada de modo que no se produzcan eventuales lesiones no sólo a los derechos sustantivos y procesales de aquélla, sino también al derecho al proceso debido del art. $6 \mathrm{CEDH}$ y a la tutela judicial del art. $24 \mathrm{CE}$

La anterior conclusión marca, o debería marcar, un punto de inflexión respecto a la exigencia de planteamiento de la cuestión prejudicial en el caso de los tribunales contra los que no cabe recurso. Efectivamente, dado que el particular no puede llevar por sí mismo su caso ante el TJUE, la eventual lesión de sus derechos consagrados en la CDFUE ha de ser protegida directamente por el juez nacional dando, en su caso, la oportunidad al TJUE a pronunciarse con carácter general sobre la materia mediante el planteamiento de la cuestión prejudicial. Resulta pues claro que hay que ser exigente a la hora de vigilar el cumplimiento de la obligación de plantear cuestión prejudicial de validez o de interpretación en el caso de los derechos fundamentales. En tal sentido debe recordarse que la negativa al planteamiento de cuestiones prejudiciales por parte de los tribunales de última instancia supone el incumplimiento de una obligación impuesta por el art. 267 (reforzado ahora por el art. 4.bis LOPJ) que viene apoyada en al menos tres sentidos. En primer lugar, puede generar la responsabilidad por incumplimiento judicial del Derecho de la UE en la medida en que la ausencia de

19 Véase supra nota 15 respecto al limitado alcance del control de derechos ejercido por el TEDH frente a los Estados cuando están aplicando Derecho de la UE. 
planteamiento de una cuestión prejudicial es uno de los criterios básicos para declarar tal responsabilidad cuando es imputable al Poder Judicial ${ }^{20}$. En segundo lugar, puede suponer una violación del art. $6 \mathrm{CEDH}^{21}$. En fin, también, puede suponer una violación del art. $24 \mathrm{CE}^{22}$.

Sin embargo, también podemos encontrar ejemplos negativos como el generado por la STS $178 / 2015$ de 24 de marzo de 2015. En esta resolución la Sala 2. ${ }^{2}$ del Tribunal Supremo, acordó la impertinencia de aplicar al caso la normativa europea sobre contabilización del tiempo de condena por el mismo delito en otro Estado miembro aplicando la legislación española de trasposición. Con independencia de que esta interpretación fuera o no correcta, lo cierto es que la Sala se dividió y los magistrados discrepantes consideraron que existía duda respecto a la interpretación que debía darse a la normativa europea. Esa división pone de manifiesto que la interpretación del Derecho de la Unión en el caso no reunía los requisitos de claridad establecidos por el TJUE en su conocida sentencia CILFIT $^{23}$ para dispensar al Tribunal contra el que no cabe recurso de su obligación de plantear la cuestión prejudicial (no concurriendo tampoco la posibilidad de que el asunto ya estuviera aclarado en la jurisprudencia europea). Al recurrente, en este caso, no le cabe más vía que intentar un recurso de amparo (y un ulterior recurso ante el TEDH) por posible violación del artículo 24 de la CE (o del 6 del CEDH) por ausencia de tal planteamiento de la cuestión prejudicial ${ }^{24}$. Sin embargo, en la jurisprudencia citada, tanto el TC (STC 232/2015) como el TEDH (STEDH Dhabbi c. Italia) declararon violación del derecho al proceso debido porque la resolución judicial carecía totalmente de motivación. No se ha producido, sin embargo, ninguna condena en este tipo de supuestos cuando la motivación existe (como es el caso de la recién citada STS 178/2015) aunque pudiera ser considerada errónea. En el peor de los casos podría ocurrir que, en un caso similar, el juez nacional que considerara, que la interpretación realizada por

20 STJUE Köbler, C-224/01, de 30 de septiembre de 2003.

21 STEDH Dhabbic. Italia (8 de abril de 2014) en el que el TEDH aplica principios sentados con anterioridad en la STEDH Vergauwen y otros c. Bélgica (10 de abril de 2012), para declarar por primera vez violación del art. $6 \mathrm{CEDH}$ por no plantear cuestión prejudicial estando obligado a ello.

22 STC 232/2015, de 5 de noviembre, también declarando violación por primera vez por no plantear cuestión prejudicial y no aplicar derecho de la UE.

23 Nos referimos a la Sentencia del Tribunal de Justica en el asunto 283/81, de 6 de octubre de 1982 en el que se fijan las condiciones que deben reunir la interpretación del derecho de la UE para que pueda considerarse un acto como claro o como aclarado. Respecto al primero sería de interés también examinar los más recientes desarrollos jurisprudenciales (flexibilizando un poco las exigencias del acto claro) en los asuntos $X$, de 9 de septiembre de 2015, C-72/14 y C-197/14 y Ferreira da Silva, de idéntica fecha, C-160/14.

24 Debe apuntarse de hecho que los afectados en el caso recurrieron al Tribunal Constitucional siendo el recurso de amparo rechazado por incumplimiento del agotamiento de los recursos previos (ausencia de planteamiento del incidente de nulidad de actuaciones). Posteriormente han recurrido ante el Tribunal Europeo de Derechos Humanos. El caso ya ha sido comunicado a España mediante escrito de 18 de enero de 2017. Caso Arrózpide Sarasola y dos recurrentes más c. España, Demanda 65101/16. Es de esperar que el TEDH aborde el problema de no planteamiento de la cuestión prejudicial cuando dicte sentencia, si bien el caso suscita problemas también desde el punto de vista de otros derechos fundamentales. 
el Tribunal Supremo no es acorde con la normativa comunitaria, planteara una cuestión prejudicial originando una Sentencia del TJUE en que se realiza una interpretación diferente e incompatible con la realizada por la Sala Segunda. Con ello se podría originar la subsiguiente responsabilidad por daños como consecuencia del incumplimiento del derecho de la Unión. Incluso, como ya ha ocurrido en nuestro país, se pudiera dar origen a una acción directa por incumplimiento judicial del Derecho de la Unión instada por la propia Comisión ${ }^{25}$.

4. En el ámbito procesal, cuando estemos en el campo de aplicación del Derecho de la UE, el precepto de referencia será el art. 47 CDFUE, pero debido al principio de autonomía institucional en materia procesal cabrá la existencia de mayores garantías derivadas del art. 24 CE siempre y cuando ello no ponga en peligro la unidad y efectividad en la aplicación del Derecho de la UE

No puede terminarse este decálogo sin entrar a valorar los efectos de la aplicación de la CDFUE en el derecho por antonomasia que vincula al juez: el derecho al debido proceso. También en este derecho fundamental hay que aplicar los mismos principios y criterios expuestos hasta ahora.

Prima facie, el Derecho procesal queda dentro del ámbito de libre configuración del legislador nacional en virtud del principio de autonomía institucional. Ahora bien, cuando las normas procesales son el mecanismo que sirve para garantizar los derechos y obligaciones derivados del Derecho de la UE habrán de respetar los parámetros derivados del art. 47 CDFUE y sólo si la unidad en la interpretación y aplicación de dicho Derecho lo permiten podrá el ordenamiento interno dar una cobertura diferente (la sentencia en el caso Melloni es cristalina en este sentido).

¿Cuál es el efecto práctico de esta afirmación para el juez?. El juez nacional continuará utilizando como parámetro ordinario de actuación en el ámbito procesal el establecido en el art. 24 CE y la jurisprudencia dictada por el TC que, ha de respetar los mínimos establecidos por el TEDH respecto al art. $6 \mathrm{CEDH}$.

Ahora bien, cuando se está juzgando un caso de aplicación de derecho de la UE resultará de aplicación el art. 47 CDFUE. Así el juez está sometido procesalmente a dos parámetros en función de cada caso concreto, pese a que la legislación procesal aplicable sea única. Y con ello se pueden generar una suerte de duplicidad de regulaciones procesales. La aplicable a los casos en los que no hay vinculo con el derecho de la Unión y la aplicable a los casos en los que existiendo tal vínculo la normativa nacional procesal no cumple alguna de las

25 Véase, Comisión c. España, C-154/2008, de 12 de noviembre de 2009. 
exigencias propias (y se entiende que exclusivas) derivadas de la CDFUE y de su artículo $47^{26}$.

El ejemplo planteado con motivo del asunto Torralbo ${ }^{27}$ puede resultar paradigmático. En este supuesto se planteaba la conformidad con el Derecho de la UE (y en particular con el art. 47) de la regulación (afortunadamente ya derogada) que establecía unas importantes tasas judiciales para poder recurrir judicialmente sentencias de primera instancia en la jurisdicción social Tasas que, a su vez, habían sido cuestionadas ante el TC. En el asunto Torralbo, el TJUE consideró que no había conexión comunitaria pues no se daban los requisitos fácticos para que el Derecho de la Unión fuera aplicable. Pero la inaplicabilidad del Derecho de la UE derivaba del supuesto fáctico concreto planteado ${ }^{28}$. Esto es, en otro supuesto de recurso en el ámbito social sometido sustancialmente a la regulación del Derecho de la UE, habría sido de aplicación la CDFUE. En tal caso, el TJUE se habría pronunciado sobre el fondo del asunto y eventualmente podría declarar que tal tasa suponía una limitación desproporcionada del derecho al recurso y con ello contrario al ejercicio de los derechos contenidos en el Derecho de la UE. Con ello se habría generado una doble regulación procesal respecto a las tasas judiciales. En el ámbito del Derecho de la UE, las tasas no serían aplicables. Fuera del ámbito del Derecho de la UE sí serían aplicables, al menos en tanto en cuanto el TC no las declarara inconstitucionales. Dos regímenes procesales distintos para dos ámbitos de aplicación diferentes.

\section{REFLEXIONES FINALES}

La última regla del decálogo enunciada puede parecer muy insatisfactoria por compleja y contraria a la seguridad e incluso a la lógica jurídica. Pero no es absurda. Para entenderlo volvamos al asunto Melloni y a la, aún más, insatisfactoria situación creada por aquella decisión, situada en el origen de la incorporación de la CDFUE, consistente en el reconocimiento de la CDFUE como un tratado de derechos fundamentales en el sentido del artículo 10.2 CE. Como decíamos al

26 Véase por ejemplo el caso Sánchez Morcillo (STJUE de 17 de Julio de 2014, C-169/14 en que se consideró contrario al art. 47 CDFUE la modificación del art. 695.4 de la LECivil (que permitía recurrir sólo al banco y no al deudor hipotecario en determinados supuestos de alegación de cláusulas abusivas en contratos hipotecarios). Sin embargo, el TC en los AATC 70/2014 y 71/2014 inadmitía por inexistencia de juicio de aplicabilidad al caso de las cuestiones de inconstitucionalidad suscitadas exactamente en el mismo tipo de supuestos y por los mismos motivos que los aceptados por el TJUE.

27 Asunto Torralbo Marcos y Korota S.A, STJUE de 27 de marzo de 2014, C-265/13.

28 En el asunto, también sobre tasas judiciales, el TJUE no entró en el fondo simplemente porque la empresa no se había declarado en estado de insolvencia (estaba en situación de concurso, no equiparable a la de insolvencia) por lo que no era de aplicación la normativa de la UE. Si la insolvencia hubiera sido declarada, automáticamente sería de aplicación al caso la CDFUE y con ella el art. 47 desplazando la aplicación del art. $24 \mathrm{CE}$. 
principio de este trabajo, en el ordenamiento español la CDFUE es Derecho de la UE y es Derecho Internacional de los Derechos Humanos. El TC al resolver definitivamente el caso tenía claramente dos opciones.

La primera opción era aplicar la CDFUE en el sentido dado por la STJUE usando el art. 93 de la CE. Si hubiera optado por tal opción, sugerida en los votos particulares, la eficacia ad extra del art. 24 CE no sería de aplicación a los supuestos en los que estuviéramos en el ámbito de aplicación del Derecho de la UE. Esto es, a las entregas o extradiciones dentro del ámbito del espacio de seguridad y justicia creado por dicho ordenamiento. El art. 24 ad extra, sin embargo, continuaría siendo de aplicación al resto de entregas o extradiciones a países no miembros de dicho espacio porque la CDFUE (y con ello la STJUE) no jugaría ningún papel en el caso. Por tanto, en todos esos supuestos España podría negarse a extraditar a condenados en juicios celebrados en ausencia en las condiciones fijadas en la jurisprudencia constitucional.

La segunda opción, seguida por la mayoría, era aplicar la CDFUE de acuerdo con la lógica del art. 10.2 CE. En tal caso, la STJUE interpretando el art. 47 CDFUE obligaba al TC a reelaborar su comprensión del art. 24 (ad extra) para cumplir con la obligación de interpretación conforme derivada del citado art. 10.2. De este modo, lo que hace el TC es realizar esa nueva interpretación reduciendo el ámbito de aplicación del art. 24 ad extra a cualquier tipo de entrega, sea o no regulada por el Derecho de la Unión y reduciendo con ello de manera generalizada, a todo tipo de recurrentes o de países reclamantes, el derecho reconocido constitucionalmente.

Esta segunda opción evita la existencia de dos regímenes diferentes en materia de aplicación del art. 24 a la extradición o entrega de personas condenadas en otros países. Unifica, a la baja, el parámetro de juicio en la materia. Esa unificación es, aparentemente, la mayor ventaja de este planteamiento. Sin embargo, presenta algunos problemas graves y que no hacen sino poner de manifiesto las dificultades del Tribunal Constitucional español para aplicar los principios básicos del Derecho de la UE.

El primero es que la inexistencia de garantías en materia procesal ante la entrega a alguien condenado en un Estado miembro del espacio de seguridad y justicia tiene pleno sentido en ese marco, pero no en otros. Efectivamente dicho espacio se asienta en un principio de confianza mutua derivado de la pertenencia de los Estados miembros a la UE (y la subsiguiente sujeción al CEDH) que hace presumir que en el funcionamiento de dichos Estados no se producen violaciones en los derechos de los ciudadanos, incluidos los derechos procesales. Existe pues, una suerte de presunción de que la protección de los derechos en todos los Estados miembros de la UE es equivalente (aunque no idéntica lo que permite regímenes distintos en materia de condenas penales en ausencia, por ejemplo) que no puede ser destruida unilateralmente por cada Estado alegando principios de derecho constitucional interno, aunque sea en materia de derechos fundamentales. Esa presunción no es, sin embargo, absoluta. Pueden producirse situaciones en las 
que la garantía de tales derechos sufra una bajada tan relevante que no se pueda mantener la confianza y con ello impedir la entrega. Este es el tipo de situación que se produce en la ya citada STJUE Aranyonsi. Si Hungría y Rumania son condenadas por violación del art. $3 \mathrm{CEDH}$ por la superpoblación de las cárceles, la normativa de la UE exigirá, como consecuencia de la necesidad de respetar el art. 4 CDFUE, que la persona afectada no sea entregada si no existen garantías suficientes de que no sufrirá la violación del derecho. Este es el sistema de derechos de la UE. Y tiene su lógica.

Como también tiene su lógica que España siga exigiendo a otros Estados unas garantías procesales mínimas para entregar a alguien condenado en ausencia en la medida en que no tenga la confianza en el funcionamiento de su sistema procesal con parámetros equivalentes a los españoles. Dicho en otros términos, la eficacia ad extra del art. 24 puede no tener sentido frente a un país miembro de la UE, pero tener pleno sentido frente a países no miembros de la UE. No es lo mismo entregar a un condenado en ausencia a Italia que entregarlo a un país africano o asiático donde la protección de los derechos no alcanza ni lejanamente los niveles europeos. Eso supone la existencia de dos regímenes diferentes en la aplicación de los derechos. Ciertamente. Pero es que ese es precisamente el sentido de la UE. La existencia para determinadas materias de un único ordenamiento común autónomo de los Estados que componen la UE. Y a ese ordenamiento le corresponden unos determinados derechos. Derechos que no tienen por qué ser exactamente iguales a los de los ordenamientos nacionales, ni mucho menos a los de los ordenamientos nacionales de estados no miembros de la UE. Este es el, a mi juicio, error que deriva de la consideración de la CDFUE como un tratado de derechos.

Pero, en segundo lugar, hay otro problema en la construcción realizada por el TC al utilizar el art. 10.2 y no el 93 de la CE para interpretar el alcance de la CDFUE. Pareciera que esta opción intenta garantizar la posición del propio TC y de la Constitución en la cúspide de la pirámide normativa y jurisdiccional. El TC, al final, acatando la STJUE lo que hace es reinterpretar el art. 24 a la luz del art. 10.2. Y no hace lo que realmente debería haber hecho, reconocer que en esa cuestión la última palabra la tiene el TJUE a partir de la interpretación del Derecho de la UE (dejando, si se quiere a salvo la posibilidad teórica de oponerse si afectara a algún elemento esencial de la constitución en aplicación de la doctrina de los contra límites) y considerar inaplicable al caso (y a todos a los que afectara la orden detención y entrega europea) la jurisprudencia relativa a la eficacia ad extra del art. 24. Esta posición puede considerarse una victoria (si es que victoria) pírrica. Efectivamente, al reconocer que la CDFUE es un tratado de derechos y que ha de interpretar la Constitución de acuerdo con la CDFUE (y por ende con la jurisprudencia del TJUE) lo que está afirmando es que en la configuración nacional del contenido de los derechos habrá de tenerse en cuenta de manera determinante (con la sola excepción de las poco probables contradicciones literales insalvables) el contenido de los derechos 
reconocidos en la CDFUE (esto es, lo que su intérprete supremo, el TJUE, sostenga que constituyen el contenido de tales derechos.) y, deberá intentar dotar de ese mismo contenido a los derechos nacionales aunque ellos suponga (como en el asunto Melloni) reducir su ámbito de protección. Si, con el TC, afirmamos que el contenido de los derechos constitucionales españoles, en todo caso, han de interpretarse conforme a la CDFUE, estaremos extendiendo los efectos (eso sí, interpretativos) de ésta (y de la jurisprudencia TJUE) más allá del Derecho de la UE. No sólo a los que se ejercen en el ámbito de la UE. En definitiva, al considerar a la CDFUE como un tratado de derechos está unificando la interpretación de la Constitución con la interpretación de la CDFUE. Podrá decirse que lo mismo ocurre con el CEDH y el TEDH, pero no es cierto porque en la estructura de funcionamiento del sistema convencional, el TEDH garantiza mínimos de protección, mientras que el sistema de la UE el TJUE garantiza la autonomía de todo un ordenamiento jurídico imponiendo estándares unitarios en los que a menudo no cabe margen de maniobra. El TC con su resolución en el asunto Melloni, y con el uso del art. 10.2, lo que hace es renunciar al margen de maniobra que le ofrecía en materia de derechos la posibilidad de desarrollar su propio discurso en el ámbito no cubierto por el Derecho de la UE y se condena a sí mismo a alterar su doctrina sobre los derechos fundamentales constitucionales siempre que no se encuentren en la línea establecida por el TJUE. Con ello renuncia aún más, a su propia posición institucional y a asumir el nuevo role en el que la integración europea le había situado: el de ser un actor más en la construcción de un espacio común, que no idéntico, de los derechos fundamentales.

En conclusión, en lugar de un triple parámetro en materia de derechos (CEDH, CE, CDFUE) en función de sus respectivos ámbitos de aplicación, como ha intentado explicar este decálogo; estaremos construyendo por vía interpretativa uno solo: el que deriva de la CDFUE tal y como la interpreta el TJUE.

No sé si este era el objetivo buscado. Es posible que, desde el punto de vista judicial y de la defensa de los derechos, acabe siendo beneficioso al dotar de más claridad al sistema resultante. Pero, personalmente, no creo que unificar en una sola carta y en un solo intérprete la protección de todos los derechos en Europa sea una buena solución.

TITLE: Judicial enforcement of the Charter of Fundamental Rights of the European Union: A Decalogue based on the ECJ case law

ABSTRACT: This essay tries to establish the basic patterns that judges must follow when facing the adjudication of the Charter of Fundamental Rights of the European Union. The basic point of reference is the case law of the European Court of Justice. But they also must be take into account the case law of the Spanish Constitutional Court and the European Court of Human Rights. After the study of the most important cases in the topic, the essay attempts to clarify when and how to follow the jurisprudence of these High Courts. 
RESUMEN: En este ensayo se pretende examinar cuáles son las pautas que ha de seguir el juez nacional cuando se enfrenta a la aplicación de la CDFUE. El punto de referencia básico en esta materia ha de ser la jurisprudencia sobre el tema del Tribunal de Justicia de la Unión Europea. De forma complementaria habrá de tenerse en cuenta la posición del Tribunal Constitucional y del Tribunal Europeo de Derechos Humanos. A partir de lo ocurrido en los casos más importantes hasta abora planteados se pretende esclarecer cuándo y cómo ha de seguirse la jurisprudencia de los tres altos tribunales.

KEY WORDS: Charter of Fundamental Rights of the European Union, Judicial enforcement, European Court of Justice, European Court of Human Rights, Constitutional Court.

Palabras clave: Carta de Derechos Fundamentales de la Unión Europea, Aplicación judicial, Tribunal de Justicia de la UE, Tribunal Europeo de Derechos Humanos, Tribunal Constitucional.

FECHA DE RECEPCIÓN: 22.12.2016

FECHA DE ACEPTACIÓN: 01.02.2017 
